\title{
О.В. Костина
}

Приволжский исследовательский медицинский университет, Нижний Новгород, Российская Федерация

\section{Роль железа в патогенезе расстройств аутистического спектра у детей}

Контактная информация:

Костина Ольга Владимировна, кандидат биологических наук, старший научный сотрудник лаборатории биохимии и неотложной диагностики ПИМУ

Адрес: 603155, Нижний Новгород, Верхне-Волжская наб., д. 18/1, тел.: +7 (8314) 36-87-13, e-mail: olkosta@rambler.ru

Статья поступила: 06.03.2018 г., принята к печати: 26.08.2018 г.

В обзоре представлен анализ механизмов влияния железа на развитие головного мозга. Рассматривается значимость дефицита железа в перинатальном периоде как фактора риска возникновения психоневрологических нарушений у детей с расстройствами аутистического спектра (РАС). Обсуждаются возможные причины сидеропении; представлены данные исследований гематологических и биохимических параметров, характеризующих обмен железа у детей с РАС. Отмечена необходимость изучения роли дисбаланса обмена железа в развитии психоневрологических нарушений для уточнения патогенетических механизмов РАС и определения способов их коррекции.

Ключевые слова: дети, расстройства аутистического спектра, железо, дефицит.

(Для цитирования: Костина О.В. Роль железа в патогенезе расстройств аутистического спектра у детей. Вопросы современной педиатрии. 2018; 17 (4): 281-286. doi: 10.15690/vsp.v17i4.1920)

\section{АКТУАЛЬНОСТЬ}

Расстройства аутистического спектра (РАC) у детей представляют собой сложные нарушения психического развития, характеризуемые проблемами в коммуникации, социальном взаимодействии, а также стереотипностью поведения (устойчивое повторение фраз, движений). Аутизм имеет полиэтиологическую природу. Установлено, что риск развития аутизма главным образом определяется генетическими факторами [1-3], в связи с чем большое внимание уделяется исследованиям генетических механизмов формирования аутизма $[4,5]$. Влияние состояний, осложняющих течение беременности (гестоз, гипоксия плода, хронические заболевания матери, патология плаценты), на развитие РАС у детей не показано однозначно. Однако вероятность возникновения РАС может повышаться при наличии предрасполагающих факторов, таких как ожирение у матери, инфекция (корь, краснуха, паротит, герпес, цитомегаловирусная инфекция), воздействие поллютантов, пестицидов [6, 7]. Совокупность всех этих факторов может привести к стойким иммунным и биохимическим изменениям (нарушение синтеза нуклеиновых кислот, нейротрансмиттеров, фосфолипидов; усиление процессов липопероксидации; перестройка иммунной системы плода вследствие усиленной продукции и трансплацентарного поступления материнских цитокинов и аутоантител), затрагивающим когнитивные функции мозга [8, 9]. К настоящему времени опубликовано большое количество работ, посвященных изучению роли дефицита железа в развитии когнитивных и поведенческих нарушений у детей с РАС. По данным зарубежных исследователей, распространенность дефицита железа у таких детей варьирует в широких пределах: по разным данным, от 8 [10] до 24-25 [11-13], 32 [14] и даже 52\% [15]. Предполагается, что изучение роли дисбаланса железа в возникновении нарушений психоневрологического характера позволит существенно дополнить и уточнить патогенетические механизмы проявлений РАС и определить возможные пути их коррекции.

\section{РОЛЬ ЖЕЛЕЗА В РАЗВИТИИ ГОЛОВНОГО МОЗГА}

Железо, будучи эссенциальным микроэлементом, является незаменимым компонентом ферментных систем организма, участвующих в аэробном

Olga V. Kostina

Privolzhskiy Research Medical University, Nizhny Novgorod, Russian Federation

\section{The Role of Iron in the Pathogenesis of Autism Spectrum Disorders in Children}

The review presents an analysis of the mechanisms of iron effect on the brain development. The importance of iron deficiency in the perinatal period is considered as a risk factor for the development of neuropsychiatric disorders in children with autism spectrum disorders (ASDs). Possible causes of sideropenia are discussed; data on haematological and biochemical parameters characterizing iron metabolism in children with ASDs are presented. The demand for studying the role of iron metabolism imbalance in the development of neuropsychiatric disorders in order to clarify pathogenetic mechanisms of ASDs and to determine methods for their correction is emphasized.

Key words: children, autism spectrum disorders, iron, deficiency.

(For citation: Kostina Olga V. The Role of Iron in the Pathogenesis of Autism Spectrum Disorders in Children. Voprosy sovremennoi pediatrii - Current Pediatrics. 2018; 17 (4): 281-286. doi: 10.15690/vsp.v17i4.1920) 
метаболизме. Установлено, что по содержанию железа клетки головного мозга уступают лишь эритроцитам [16]. Наибольшая его концентрация содержится в олигодендроцитах, основная функция которых - миелинизация нервных волокон [17]. Дефицит железа сопровождается снижением синтеза миелина, что в итоге приводит к низкой скорости передачи возбуждения по нервным волокнам [18]. Как показали эксперименты in vivo, низкий уровень железа в головном мозге сопряжен с нарушением пролиферации клеток-предшественников олигодендроцитов. Это может служить одним из возможных объяснений сниженного числа олигодендроцитов у взрослых животных после перенесенной железодефицитной анемии [19]. Сидеропения способствует нарушению глиальной функции нейронов и обмена моноаминов, что приводит к замедлению арборизации (ветвления) дендритов - процесса, наиболее активно протекающего в раннем возрасте [20].

Железо является кофактором для триптофан- и тирозингидроксилазы, которые необходимы для синтеза серотонина из триптофана и норадреналина, а также дофамина из тирозина [10]. Уменьшение концентрации железа в мозге на 15\% приводит к изменениям в дофаминергической системе, что проявляется заторможенностью когнитивных процессов, инертностью, нарушениями поведения, моторики [21].

Дефицит железа в мозге вызывает уменьшение активности глутаматдекарбоксилазы и трансаминазы гамма-аминомасляной кислоты, влияя таким образом на метаболизм важнейшего нейромедиатора - гаммааминомасляной кислоты [22]. При этом страдают системы опиатной, а также холинергической передачи нервного импульса в результате отмечаемого на фоне сидеропении снижения концентрации холина - предшественника ацетилхолина [23].

Железо необходимо для функционирования фермента рибонуклеотидредуктазы, поэтому недостаток этого микроэлемента приводит к замедлению синтеза ДНК и пролиферации клеток, в том числе и клеток центральной нервной системы [24]. В результате нарушения поступления железа в ткани мозга отмечается снижение активности окислительно-восстановительных ферментов - цитохромоксидазы, каталазы, супероксиддисмутазы, сукцинатдегидрогеназы [25].

Усиление свободнорадикальных процессов также может быть одной из причин повреждений биомолекул В клетках центральной нервной системы. Взаимодействие ионов двухвалентного железа с перекисью водорода в реакции Фентона инициирует образование активных форм кислорода [26], которые в свою очередь могут повлиять на геномную стабильность в периоды синтеза ДНК и пролиферации клеток в процессе развития мозга [27, 28]. Наиболее чувствительными генетическими мишенями при действии активных форм кислорода на ДНК являются основания гуанина, а продуктом их повреждения - основной биомаркер окислительного повреждения ДНК 8-оксогуанин (8-гидроксигуанин) [29]. Это соединение обладает способностью образовывать ошибочные пары как с цитозином, так и с аденином, что обусловливает мутационные трансверсии [30].

\section{ВЛИЯНИЕ ПЕРИНАТАЛЬНОГО ДЕФИЦИТА ЖЕЛЕЗА НА РАЗВИТИЕ КОГНИТИВНЫХ И ПОВЕДЕНЧЕСКИХ НАРУШЕНИЙ У ДЕТЕЙ В РАННЕМ ВОЗРАСТЕ}

Учитывая важное значение железа в процессе нейрогенеза плода среди многочисленных пренатальных факторов риска развития РАС, особое внимание уделя- ется железодефицитной анемии беременных, имеющей множество причин развития: снижение уровня железа в крови в результате его недостаточного потребления, неэффективного поглощения или обмена веществ [31]; возрастание потребности в железе клетками фетоплацентарного комплекса и увеличение объема циркулирующей крови; патологии печени вследствие нарушения обмена белков, участвующих в метаболизме железа (ферритина, гемосидерина, трансферрина и др.). К числу факторов риска железодефицитной анемии у беременных относят частые роды, ранние гестозы, многоплодие, инфекционно-хронические заболевания, нарушения функции щитовидной железы, миому, эндометриоз, а также беременность, наступившую на фоне лактации $[32,33]$. Железодефицитная анемия оказывает негативное влияние как на течение беременности и родов, так и на состояние плода и новорожденного вследствие развития в организме матери гипоксии [34]. Беременность на фоне железодефицитной анемии чаще осложняется хронической маточно-плацентарной недостаточностью [35], внутриутробными инфекциями [36], гестозом и угрозой прерывания [37].

Одним из механизмов развития РАС может быть активация свободнорадикальных процессов при гипоксии, вызванной анемией при беременности. Усиление свободнорадикального окисления на фоне недостаточности антиоксидантной системы защиты у беременных с железодефицитной анемией способствует нарушению метаболизма и функций жизненно важных органов, в том числе и плаценты, способствуя гипоксии и гипотрофии плода [38], а также нарушению нормального развития его органов, в том числе головного мозга [39].

Метаболические нарушения, такие как ожирение и диабет у беременных, усугубляют дефицит железа [40]. Установлено, что при ожирении и диабете у беременных частота развития РАС у их детей возрастает в 1,7 раза, задержек развития - в 2 раза [6], что может быть связано с действием провоспалительных цитокинов на головной мозг плода, а также гипергликемией, обусловливающей развитие гипоксии и окислительный стресс в тканях плода [41]. Сочетание метаболического синдрома беременных и низкого потребления железа ассоциировано почти с пятикратным повышением риска развития РАC [42].

Еще одним независимым фактором риска развития РАС является пренатальное воспаление, которое может привести к цитокинопосредованному снижению уровня железа [43]. Высокая восприимчивость к инфекциям при железодефицитной анемии связана с увеличением экспрессии интерлейкина (Interleukin, IL) 6 в ответ на воспаление, активирующее продукцию гепсидина гепатоцитами [44]. Как отрицательный регулятор метаболизма железа, гепсидин оказывает блокирующее воздействие на любой транспорт железа из разных клеток и тканей (из энтероцитов, макрофагов, гепатоцитов, плаценты) [45]. Выход железа из клеток ретикулоэндотелиальной системы блокируется в результате комплексного действия гепсидина и липополисахаридов микробов, направленного на деградацию ферропортина - трансмембранного белка, транспортирующего железо из клетки [46, 47]. Одновременно цитокины и липополисахариды стимулируют абсорбцию и удержание железа фагоцитами. Так, IL1, 6 и 10 усиливают продукцию ферритина [48]. IL10 активирует рецепторы к трансферрину [49]. Фактор некроза опухоли $\alpha$ и интерферон $\gamma$ способствуют угнетению синтеза эритропоэтина, ингибируют дифференцировку и пролиферацию клеток эритроидного ряда [50]. В итоге эти процессы приводят к сидеропении, угнетению 
эритропоэза и развитию анемии [51]. Показано, что прием препаратов железа беременными предотвращает последствия гипоферремии, обусловленной воспалением [52]. В последние годы опубликованы данные о том, что причиной анемии у беременных является не только непосредственно дефицит железа, но и снижение уровня эритропоэтина на фоне инфекционно-воспалительных заболеваний [20].

Учитывая, что железодефицитная анемия у беременных может оказывать влияние на психомоторное развитие и нарушение когнитивных функций у детей, обращает на себя внимание тот факт, что у детей раннего возраста с анемией легкой или средней степени тяжести матери во время беременности чаще имели соответственную тяжесть анемии - легкую или среднюю [53]. Данные о восполнении дефицита железа у беременных свидетельствуют, что у матерей, чьи дети развили РАС, было низкое общее потребление железа в сравнении с женщинами, имеющими детей с нормальным развитием [7].

В соответствии с рекомендациями Всемирной организации здравоохранения по лечению и профилактике железодефицитной анемии все беременные и кормящие женщины в первые 6 мес лактации должны получать препараты железа [54]. Предполагается, что поддержание нормального уровня железа может способствовать снижению риска возникновения развития психоневрологических расстройств у детей.

\section{ОСОБЕННОСТИ ОБМЕНА ЖЕЛЕЗА У ДЕТЕЙ С РАССТРОЙСТВАМИ АУТИСТИЧЕСКОГО СПЕКТРА}

Среди многих факторов, оказывающих влияние на развитие детей, несомненная роль принадлежит дефициту железа, который как в антенатальном периоде, так и в первые годы жизни может негативно воздействовать на становление психомоторных, речевых, поведенческих реакций, память и мышление [17]. Первые два года являются для ребенка особенно "уязвимыми" в отношении отрицательного влияния недостатка железа на центральную нервную систему, поскольку этот период характеризуется активным развитием головного мозга (завершение миелинизации нейронов, формирование гиппокампа, активный дендрито- и синаптогенез) [20].

Данные о параметрах, характеризующих обмен железа у детей с PAC, неоднозначны. Так, E. Reynolds и соавт. [10] в исследовании 222 пациентов с РАС показали, что у 18 человек была снижена концентрация ферритина, у 2 - концентрация ферритина и трансферрина, у 7 - уровень гемоглобина, а железодефицитная анемия (на основании показателей гемоглобина и ферритина) была выявлена лишь у 1 пациента.

S. Herguner и соавт. [12], изучив данные 116 детей с РАC, обнаружили дефицит железа у $24 \%$ пациентов, железодефицитную анемию - у 16\%. Была продемонстрирована положительная корреляционная связь между возрастом детей и концентрацией ферритина.

S. Gunes и соавт. [13], обследовав 100 пациентов с РАС, выявили сидеропению у 25\% (в контрольной группе детей - у 15\%), железодефицитную анемию - у 13\% (в контрольной группе - у 6\%). При этом у детей с РАС было обнаружено снижение концентраций гемоглобина, железа, уровня гематокрита и среднего объема эритроцитов. Содержание ферритина практически не отличалось от такового у детей контрольной группы. Вместе с тем у детей с РАС в возрасте младше 6 лет отмечалось выраженное, статистически значимое снижение уровней железа, гемоглобина, гематокрита и среднего объема эритроцитов, а также незначительное снижение уровня ферритина по сравнению детьми старше 6 лет. Кроме того, было показано, что максимальная частота железодефицитной анемии (24\%) отмечалась среди детей с тяжелыми проявлениями PAC (согласно шкале Childhood Autism Rating Scale), тогда как среди детей с умеренными проявлениями РАС железодефицитная анемия обнаруживалась в единичных случаях (2\%) [13].

Отмечается, что низкий уровень железа в крови может быть вызван селективностью при выборе продуктов питания (вплоть до очень ограниченного рациона в связи со вкусовыми, обонятельными, цветовыми пристрастиями к еде, особенностями ее консистенции), которая наблюдается чаще при аутизме (60\%), чем у детей с нормальным развитием (22\%) [55]. Поскольку дети младшего возраста с аутизмом в большей мере избирательны в отношении того, что они едят, именно этим фактом объясняется более распространенный дефицит железа в этой возрастной группе [56]. По данным C. Dosman и соавт. [57], число дошкольников с РАС, имеющих недостаточное потребление железа с пищей, превышает число детей школьного возраста с аналогичной патологией почти в 2 раза - 69 и 35\% соответственно. Однако в другом исследовании [10] было показано, что низкое содержание железа не связано с недостаточным его потреблением с пищей. Тем не менее при планировании рациона ребенка с РАС необходимо стремиться к тому, чтобы питание было полноценным и сбалансированным, и в первую очередь содержало хорошо усваиваемое гемовое железо, входящее в состав продуктов животного происхождения. Однако даже скорректированная диета не может в полной мере устранить дефицит этого микроэлемента в организме, в связи с чем необходима дополнительная терапия препаратами железа [25].

В публикациях приводятся различные данные о частоте встречаемости желудочно-кишечных расстройств у детей с РАC - от 9 до 91\% [55, 58, 59]. Среди желудочно-кишечных расстройств преобладают запоры, диарея, повышенное газообразование, а также боли в животе [60, 61] одной из причин которых может быть пищевая стереотипия вследствие недостатка либо непереносимости тех или иных пищевых компонентов. Адресный, индивидуализированный подбор диеты может способствовать снижению выраженности симптомов дисфункции желудочно-кишечного тракта у детей с аутизмом [62]. Вместе с тем тяжелые органические повреждения желудочно-кишечного тракта не характерны для детей с РАС. В частности, в исследовании S. Ibrahim и соавт. [63] был выявлен лишь один случай болезни Крона и один - панкреатита у 124 наблюдаемых детей с РАС. Отмечается также, что при РАС нарушена проницаемость кишечника, а серотонин, действующий как провоспалительный модулятор, может угрожать развитием гастроинтестинальных нарушений [57].

Можно предположить, что дефицит железа у детей с РАС вызван нарушением его всасывания в кишечнике. Получены данные о гипероксалемии и гипероксалурии у детей с РАC [64], которые могут быть вовлечены в патогенез заболевания и являться причиной нарушения усвояемости железа. Оксалаты входят в комплекс с железом и снижают его всасываемость, а также оказывают влияние на скорость высвобождения трансферрином этого микроэлемента [65]. Реакция оксалатов с трансферрином не является ведущей причиной развития железодефицитной анемии при аутизме, но исключить этот фактор нельзя [66]. Причины повышения концентрации оксалатов при аутизме не установлены: возможно, это результат нарушения почечной экскреции или усиленной кишечной абсорбции [64]. 
В исследованиях, проведенных 0. Gebril и N. Meguid [67], а также Y. Han и соавт. [68], отмечается роль окислительного стресса в функционировании клеток центральной нервной системы у детей-аутистов. Авторами были выявлены гипергомоцистеинемия, повышение уровня малонового диальдегида, снижение активности супероксиддисмутазы и глутатионпероксидазы, концентраций церулоплазмина и трансферрина - транспортного белка железа.

Указывается значимость ферритина как индикатора дефицита железа при РАС. Однако отмечается, что, будучи острофазным белком, он может давать завышенные результаты при наличии инфекции $[11,14,69]$. Выявлено, что у 44-83\% детей с РАС имеются нарушения сна на фоне низких значений сывороточного железа и ферритина. Эти нарушения корригировались препаратами железа, на основании чего авторы сделали вывод о взаимосвязи дефицита железа и плохого сна [58, 70]. Однако другие исследователи [71] получили противоположные результаты: не было выявлено различий между значениями уровня ферритина у обследованных пациентов и здоровых детей и, соответственно, его связи с характеристиками полисомнограммы. Таким образом, изучение значимости ферритина и его связи с нарушениями сна у детей с РАС требует дальнейших исследований.

В связи со сложностями, которые могут возникнуть при взятии крови у детей с РАС, представляет интерес возможность оценки уровня железа в волосах. Однако полученные в результате масс-спектрометрических исследований сведения о содержании железа в волосах детей с РАС противоречивы. Так, Y. Al-Farsi и соавт. [72] выявили у детей с РАС значительно более высокое содержание железа в волосах, чем у здоровых детей. Отмечена также ассоциация содержания железа в волосах у детей с РАС с частотой возникновения острых респираторных инфекций [73]. Обнаружены возрастные отличия в содержании этого микроэлемента: у детей 6-10 лет концентрация железа в волосах была на 21\% выше, чем у здоровых детей, тогда как в младшей группе (2-5 лет) таких различий не обнаружено. Следует отметить, что указанные различия были подтверждены только для мальчиков. Исследования содержания железа в волосах у пациентов c РАC показало наличие ассоциации этого параметра с речевым развитием детей в младшей возрастной груп- пе (2-4 года), но не детей старшего возраста [74]. Вместе с тем результаты метаанализа [75] продемонстрировали значительное снижение концентрации железа в волосах детей с РAC, а проведенные E. Blaurock-Busch и соавт. исследования [76] не подтвердили корреляции содержания этого микроэлемента в волосах с наличием коммуникативных и когнитивных нарушений у детей с PAC.

\section{ЗАКЛЮЧЕНИЕ}

К настоящему времени накоплен обширный материал, показывающий, что дефицит железа может оказывать влияние на развитие мозга и вызывать отдаленные расстройства когнитивной и поведенческой сфер жизнедеятельности детей. Несмотря на внимание зарубежных исследователей к изучению роли дефицита железа в патогенезе аутизма, в нашей стране этот вопрос изучался лишь в единичных исследованиях. Не ясно, какие пороговые значения дефицита железа являются решающими для развития аутизма; не установлены оптимальные дозы препаратов железа, способные снижать риск развития этого заболевания при их приеме во время беременности. Остаются также невыясненными до конца причины дефицита железа у детей с РАС и степень его влияния на выраженность когнитивных и поведенческих нарушений. Решение этих вопросов поможет выявить возможные патогенетические пути развития аутизма и определить эффективные подходы к коррекции данного заболевания.

\section{ИСТОЧНИК ФИНАНСИРОВАНИЯ}

Не указан.

\section{FINANCING SOURCE}

Not specified.

\section{КОНФЛИКТ ИНТЕРЕСОВ}

Автор статьи подтвердил отсутствие конфликта интересов, о котором необходимо сообщить.

\section{CONFLICT OF INTERESTS}

Not declared.

\section{ORCID}

О. В. Костина http://orcid.org/0000-0001-7529-2544

\section{СПИСОК ЛИТЕРАТУРЫ}

1. Betancur C. Etiological heterogeneity in autism spectrum disorders: more than 100 genetic and genomic disorders and still counting. Brain Res. 2011;1380:42-77. doi: 10.1016/ j.brainres.2010.11.078.

2. Geschwind DH. Genetics of autism spectrum disorders. Trends Cogn Sci. 2011;15(9):409-416. doi: 10.1016/j.tics. 2011.07.003.

3. Бобылова М.Ю., Печатникова Н.Л. Генетика аутизма (Обзор зарубежной литературы) // Российский журнал детской неврологии. - 2013. - Т. 8. - № 3 - С. 31-45. [Bobylova MY, Petchatnikova HL. Genetics of autistic disorder (review of foreign literature). Russian Journal of Child Neurology. 2013;8(3):31-45. (In Russ).] doi: 10.17650/2073-88032013-8-3-31-45.

4. Новосёлова О.Г., Каркашадзе Г.А., Журкова Н.В., Маслова О.И. Перспективы диагностики расстройств аутистического спектра у детей // Вопросы современной педиатрии. - 2014. T. 13. - № 3- C. 61-68. [Novoselova OG, Karkashadze GA, Zhurkova NV, Maslova OI. Prospects of diagnostics of autism spectrum disorders in children. Current pediatrics. 2014;13(3):61-68. (In Russ).] doi: 10.15690/vsp.v13i3.1029.

5. Baker E, Jeste SS. Diagnosis and management of autism spectrum disorder in the era of genomics: rare disorders can

pave the way for targeted treatments. Pediatr Clin North Am. 2015;62(3):607-618. doi: 10.1016/j.pcl.2015.03.003.

6. Schmidt RJ, Tancredi DJ, Krakowiak P, et al. Maternal intake of supplemental iron and risk of autism spectrum disorder. Am $J$ Epidemiol. 2014;180(9):890-900. doi: 10.1093/aje/kwu208.

7. Abruzzo PM, Ghezzo A, Bolotta A, et al. Perspective biological markers for autism spectrum disorders: advantages of the use of receiver operating characteristic curves in evaluating marker sensitivity and specificity. Dis Markers. 2015;2015:329607. doi: 10.1155/2015/329607.

8. Чуприков А.П., Хворова А.М. Расстройства спектра аутизма: медицинская и психолого-педагогическая помощь. - Львов: Мс; 2013. [Chuprikov AP, Khvorova AM. Rasstroistva spektra autizma: meditsinskaya i psikhologo-pedagogicheskaya pomoshch'. Lvov: Ms; 2013. (In Russ).]

9. Полетаев А.Б., Шендеров Б.А. Аутизм и иммунитет: генетика или эпигенетика? // Клиническая патофизиология. - 2016. T. 22. - № $4-$ C. 17-25. [Poletaev AB, Shenderov BA. Autism and autoimmunity: genetics or epigenetics? Clinical pathophysiology. 2016;22(4):17-25. (In Russ).]

10. Reynolds A, Krebs NF, Stewart PA, et al. Iron status in children with autism spectrum disorder. Pediatrics. 2012;130 Suppl 2: S154-159. doi: 10.1542/peds.2012-0900M. 
11. Dosman CF, Drmic IE, Brian JA, et al. Ferritin as an indicator of suspected iron deficiency in children with autism spectrum disorder: prevalence of low serum ferritin concentration. Dev Med Child Neurol. 2006;48(12):1008-1009. doi: 10.1017/S0012162206232225. 12. Herguner S, Kelesoglu FM, Tanidir C, Copur M. Ferritin and iron levels in children with autistic disorde. Eur J Pediatr. 2012; 171(1):143-146. doi: 10.1007/s00431-011-1506-6.

13. Gunes S, Ekinci O, Celik T. Iron deficiency parameters in autism spectrum disorder: clinical correlates and associated factors. Ital J Pediatr. 2017;43(1):86. doi: 10.1186/s13052-017-0407-3.

14. Bilgic A, Gurkan K, Turkoglu S, et al. Iron deficiency in preschool children with autistic spectrum disorders. Res Autism Spectr Disord. 2010;4(4):639-644. doi: 10.1016/j.rasd.2009.12.008.

15. Latif A, Heinz P, Cook R. Iron deficiency in autism and Asperger syndrome. Autism. 2002;6(1):103-114. doi: 10.1177/ 1362361302006001008.

16. Кудрин А.В., Громова О.А. Микроэлементы в иммунологии и онкологии. - М.: ГЭОТАР-Медиа; 2007. [Kudrin AV, Gromova OA. Mikroelementy v immunologii i onkologii. Moscow: GEOTAR-Media; 2007. (In Russ).]

17. Диагностика и лечение железодефицитной анемии у детей и подростков (пособие для врачей) / Под ред. Румянцева А.Г., Захаровой И.Н. - М.: Конти принт; 2015. [Diagnostika i lechenie zhelezodefitsitnoi anemii u detei i podrostkov (posobie dlya vrachei). Ed by Rumyantsev AG, Zakharova IN. Moscow: Konti print; 2015. (In Russ).]

18. Kwik-Uribe CL, Gietzen D, German JB, etal. Chronic marginal iron intakes during early development in mice result in persistent changes in dopamine metabolism and myelin composition. $J$ Nutr. 2000;130(11):2821-2830. doi: 10.1093/jn/130.11.2821.

19. Morath DJ, Mayer-Proschel M. Iron deficiency during embryogenesis and consequences for oligodendrocyte generation in vivo. Dev Neurosci. 2002;24(2-3):197-207. doi: 10.1159/000065688.

20. Богданова Н.М., Булатова Е.М., Габрусская Т.В., Верхососова А.В. Дефицит железа и его отрицательное влияние на развитие детей раннего возраста. Диетологические возможности постнатальной коррекции дефицита железа // Лечащий врач. - 2011. - № 8. - C. 38-44. [Bogdanova NM, Bulatova EM, Gabrusskaya TV, Verkhososova AV. Defitsit zheleza i ego otritsatel'noe vliyanie na razvitie detei rannego vozrasta. Dietologicheskie vozmozhnosti postnatal'noi korrektsii defitsita zheleza. Practitioner. 2011;(8):38-44. (In Russ).]

21. Beard JL. Iron biology in immune function, muscle metabolism and neuronal functioning. J Nutr. 2001;131(2S-2):568S-579S. doi: $10.1093 / \mathrm{jn} / 131.2 .568 \mathrm{~S}$.

22. Agarwal KN. Iron and the brain: neurotransmitter receptors and magnetic resonance spectroscopy. Br J Nutr. 2001;85 Suppl 2: 147-150. doi: 10.1049/BJN2000307.

23. Shukla A, Agarwal KN, Shukla GS. Latent iron deficiency alters gamma-aminobutyric acid and glutamate metabolism in rat brain. Experientia. 1989;45(4):343-345. doi: 10.1007/bf01957472.

24. Захарова И.Н., Мачнева Е.Б. Влияние микронутриентов на когнитивное развитие детей // Педиатрия. Приложение к журналу Consilium Medicum. — 2014. — № 2 - C. 16-20. [Zakharova IN, Machneva EB. Vliyanie mikronutrientov na kognitivnoe razvitie detei. Pediatriya. Prilozhenie k zhurnalu Consilium Medicum. 2014;(2): 16-20. (In Russ).]

25. Захарова И.Н., Дмитриева Ю.А. Железодефицитные состояния как причина нарушений когнитивного развития у детей // Эффективная фармакотерапия. - 2012. - № 33 - С. 42-46. [Zakharova IN, Dmitrieva YuA. Zhelezodefitsitnye sostoyaniya kak prichina narushenii kognitivnogo razvitiya u detei. Effektivnaya farmakoterapiya. 2012;(33):42-46. (In Russ).]

26. Halliwell B. Oxidative stress and neurodegeneration: where are we now? J Neurochem. 2006;97(6):1634-1658. doi: 10.1111/ j.1471-4159.2006.03907.x

27. Larsen E, Reite K, Nesse G, et al. Repair and mutagenesis at oxidized DNA lesions in the developing brain of wild-type and Ogg1-/- mice. Oncogene. 2006;25(17):2425-2432. doi: 10.1038/ sj.onc.1209284.

28. Song L, Zheng J, Li H, et al. Prenatal stress causes oxidative damage to mitochondrial DNA in hippocampus of offspring rats. Prenatal Neurochem Res. 2009;34(4):739-745. doi: 10.1007/ s11064-008-9838-y.

29. Pra D, Franke SI, Henriques JA, Fenech M. Iron and genome stability: an update. Mutat Res. 2012;733(1-2):92-99. doi: 10.1016/j.mrfmmm.2012.02.001.
30. Gushima M, Hirahashi M, Matsumoto T, et al. Altered expression of MUTYH and an increase in 8-hydroxydeoxyguanosine are early events in ulcerative colitis-associated carcinogenesis. I Pathol. 2009;219(1):77-86. doi: 10.1002/path.2570.

31. Занько С.Н. Железодефицитная анемия и беременность // Охрана материнства и детства. - 2005. - № 1-6 - С. 31-39. [Zan'ko SN. Zhelezodefitsitnaya anemiya i beremennost'. Okhrana materinstva i detstva. 2005;(1-6):31-39. (In Russ).]

32. Протопопова Т.А. Железодефицитная анемия и беременность // Российский медицинский журнал. - 2012. - Т. 20. № 17 - C. 862-866. [Protopopova TA. Zhelezodefitsitnaya anemiya i beremennost'. Rossiiskii meditsinskii zhurnal. 2012;20(17): 862-866. (In Russ).]

33. Пересада О.А., Котова Г.С., Солонко И.И. Железодефицитная анемия при беременности // Медицинские новости. - 2013. № 2 - C. 6-12. [Peresada OA, Kotova GS, Solonko II. Iron deficiency anemia in pregnancy. Meditsinskie novosti. 2013;(2):6-12. (In Russ).]

34. Логутова Л.С., Ахвледиани К.Н., Петрухин В.А., и др. Профилактика фетоплацентарной недостаточности и перинатальных осложнений у беременных с железодефицитной анемией // Российский вестник акушера-гинеколога. - 2009. - № 5 C. 672-677. [Logutova LS, Akhvlediani KN, Petrukhin VA, et al. Prevention of fetoplacental insufficiency and perinatal complications in pregnant women with iron-deficiency anemia. Rossiiskii vestnik akushera-ginekologa. 2009;(5):672-677. (In Russ).]

35. Боровкова Л.В., Волкова С.А., Воронина И.Д. Роль железодефицитной анемии в генезе плацентарной недостаточности // Медицинский альманах. - 2010. - № 4 - С. 97-101. [Borovkova LV, Volkova SA, Voronina ID. The role of iron-deficiency anemia in the genesis of placental insufficiency. Meditsinskii al'manakh. 2010;(4):97-101. (In Russ).]

36. Новикова С.В., Логутова Л.С., Бочарова И.И. Оптимизация ведения беременных с высоким инфекционным риском // Российский медицинский журнал. - 2015. - Т. 23. - № 1 C. 6-9. [Novikova SV, Logutova LS, Bocharova II. Optimizatsiya vedeniya beremennykh s vysokim infektsionnym riskom. Rossiiskii meditsinskii zhurnal. 2015;23(1):6-9. (In Russ).]

37. Даниялова Х.М., Ухманова М.М., Доронин Г.Л., и др. Железодефицитная анемия у беременных. Клиника, диагностика, профилактика и лечение // Проблемы женского здоровья. 2013. - T. 8. - № 1 - C. 58-63. [Daniyalova HM, Uhmanova MM, Doronin GL, et al. Iron-deficiency anemia in pregnancy. Clinic, diagnostics, prevention and treatment. Problemy zhenskogo zdorov'ya. 2013;8(1):58-63. (In Russ).]

38. Гончарова Е.В., Говорин А.В. Динамика показателей перекисного окисления липидов и антиоксидантной защиты крови у больных железодефицитной анемией на фоне лечения препаратами железа и селена // Забайкальский медицинский вестник. - 2014. - № 2 - C. 64-68. [Goncharova EV, Govorin AV. Dinamika pokazatelei perekisnogo okisleniya lipidov i antioksidantnoi zashchity krovi u bol'nykh zhelezodefitsitnoi anemiei na fone lecheniya preparatami zheleza i selena. Zabaikal'skii meditsinskii vestnik. 2014;(2):64-68. (In Russ).]

39. Кулакова В.А., Боташева Т.Л., Орлов А.В., Зенкина З.В. Прогнозирование гипоксически-ишемических поражений мозга плода при оценке оксидантно-антиоксидантного статуса беременных накануне родов // Современные проблемы науки и образования. - 2015. - № 1. [Kulakova VA, Botasheva TL, Orlov AV, Zenkina ZV. Prediction of hypoxic ishemic brain damage of the fetus in assesing the oxidant status of pregnant women before delivery. Modern problems of science and education. 2015;(1). (In Russ).] Доступно по http://science-education.ru/ru/article/ view?id=17818. Ссылка активна на 14.06.2018.

40. Саприна Т.В., Прохоренко Т.С., Мусина Н.Н., и др. Механизмы развития анемии хронических заболеваний у беременных с сочетанием гестационного диабета. / Российская мультидисциплинарная конференция с международным участием “Сахарный диабет - 2017: от мониторинга к управлению»; Апрель 19-20, 2017; Новосибирск. - Новосибирск; 2017. - С. 129-131. [Saprina TV, Prohorenko TS, Musina NN, et al. Mekhanizmy razvitiya anemii khronicheskikh zabolevanii u beremennykh s sochetaniem gestatsionnogo diabeta. (Conference proceedings) Rossiiskaya mul'tidisciplinarnaya konferentsiya s mezhdunarodnym uchastiem "Saharnyi diabet - 2017: ot monitoringa k upravleniyu"; $2017 \mathrm{apr}$ 19-20; Novosibirsk. Novosibirsk; 2017. pp. 129-131. (In Russ).] 
41. Li M, Fallin MD, Riley A, et al. The association of maternal obesity and diabetes with autism and other developmental disabilities. Pediatrics. 2016;137(2):e20152206. doi: 10.1542/ peds.2015-2206.

42. Krakowiak P, Walker CK, Bremer AA, et al. Maternal metabolic conditions and risk for autism and other neurodevelopmental disorders. Pediatrics. 2012;129(5):1121-1128. doi: 10.1542/ peds.2011-2583.

43. Zerbo 0 , Iosif AM, Walker C, et al. Is maternal influenza or fever during pregnancy associated with autism or developmental delays? Results from the CHARGE (Childhood Autism Risks from Genetics and Environment) study. J Autism Dev Disord. 2013;43(1):25-33. doi: $10.1007 /$ s10803-012-1540-x.

44. Nemeth E, Revera S, Gabayan V, Ganz T. IL-6 mediates hypoferremia of inflammation by inducing the synthesis of the iron regulatory hormone hepcidin. J Clin Invest. 2004;113(9): 1271-1276. doi: 10.1172/JCl20945.

45. Беловол А.Н., Князькова И.И. От метаболизма железа к вопросам фармакологической коррекции его дефицита // Ліки України. - 2015. - № 4- C. 74-83. [Belovol AN, Knyaz'kova II. Ot metabolizma zheleza - k voprosam farmakologicheskoi korrektsii ego defitsita. Liky Ukrai'ny. 2015;(4):74-83. (In Russ).]

46. Delaby C, Pilard N, Goncalves AS, et al. Presence of the iron exporter ferroportin at the plasma membrane of macrophages is enhanced by iron loading and down-regulated by hepcidin. Blood. 2005;106(12):3979-3984. doi: 10.1182/blood-2005-06-2398.

47. Deschemin JC, Vaulont S. Role of hepcidin in the setting of hypoferremia during acute inflammation. PloS One. 2013; 8(4):e61050. doi: 10.1371/journal.pone.0061050.

48. Koorts AM, Viljoen M. Acute phase proteins: ferritin and ferritin isoforms. In: Veas PF, editor. Acute phase proteins - regulation and functions of acute phase proteins. London, UK: IntechOpen; 2011. doi: $10.5772 / 20586$.

49. Новикова И.А. Железо и иммунный ответ (лекция) // Проблемы здоровья и экологии. - 2011. - № 4 - С. 42-48. [Novikova IA. Iron and immune response. Problemy zdorov'ya $i$ ekologii. 2011;(4):42-48. (In Russ).]

50. Morceau F, Dicato M, Diederich M. Pro-inflammatory cytokinemediated anemia: regarding molecular mechanisms of erythropoiesis. Mediators Inflamm. 2009;2009:405016. doi: 10.1155/ $2009 / 405016$.

51. Тарасова Н.Е., Теплякова Н.Д. Феррокинетика и механизмы ее регуляции в организме человека // Журнал фундаментальной медицины и биологии. - 2012. - № 1 - C. 10-16. [Tarasova NE, Teplyakova ND. Ferrokinetics and the mechanisms of iys regulation in human organism. Zhurnal fundamental'noi meditsiny $i$ biologii. 2012;(1):10-16. (In Russ).]

52. Aguilar-Valles A, Flores C, Luheshi GN. Prenatal inflammationinduced hypoferremia alters dopamine function in the adult offspring in rat: relevance for schizophrenia. PLoS One. 2010;5(6):e10967. doi: 10.1371/journal.pone.0010967.

53. Верещагина В.С., Зауралов Е.О., Раздолькина Т.И., Науменко Е.И. Особенности железодефицитной анемии у детей раннего возраста г. Саранска // Медицинский альманах. - 2017. № 2 - C. 42-47. [Vereshchagina VS, Zauralov EO, Razdolkina TI, Naumenko El. Peculiarities of asiderotic anemia of early age children in Saransk. Medicinskii al'manakh. 2017;(2):42-47. (In Russ).]

54. Michaelsen KF, Weaver L, Branca F, Robertson A. Feeding and nutrition of infants and young children [Internet]. Denmark: WHO; 2000. p. 87 [cited 2018 Jun 23]. Available from: http://apps.who. int/iris/bitstream/handle/10665/272658/9289013540-eng. pdf? sequence $=1 \&$ isAllowed $=\mathrm{y}$.

55. Valicenti-McDermott M, McVicar K, Rapin I, et al. Frequency of gastrointestinal symptoms in children with autistic spectrum disorders and association with family history of autoimmune disease. J Dev Behav Pediatr. 2006;27(2 Suppl):S128-136. doi: 10.1097/00004703-200604002-00011.

56. Xia W, Zhou Y, Sun C, et al. A preliminary study on nutritional status and intake in Chinese children with autism. Eur J Pediatr. 2010;169:1201-1206. doi: 10.1007/s00431-010-1203-x.

57. Dosman CF, Brian JA, Drmic IE, et al. Children with autism: effect of iron supplementation on sleep and ferritin. Pediatr Neurol. 2007;36(3):152-158. doi: 10.1016/j.pediatrneurol.2006.11.004. 58. Molloy CA, Manning-Courtney P. Prevalence of chronic gastrointestinal symptoms in children with autism and autistic spectrum disorders. Autism. 2003;7(2):165-171. doi: 10.1177/ 1362361303007002004.

59. Coury DL, Ashwood P, Fasano A, et al. Gastrointestinal conditions in children with autism spectrum disorder: developing a research agenda. Pediatrics. 2012;130 Suppl 2:160-168. doi: 10.1542/ peds.2012-0900N.

60. Wang LW, Tancredi DJ, Thomas DW. The prevalence of gastrointestinal problems in children across the United States with autism spectrum disorders from families with multiple affected members. J Dev Behav Pediatr. 2011;32(5):351-360. doi: 10.1097/ DBP.0b013e31821bd06a.

61. Gorrindo P, Williams KC, Lee EB, et al. Gastrointestinal dysfunction in autism: parental report, clinical evaluation, and associated factors. Autism Res. 2012;5(2):101-108. doi: 10.1002/aur.237

62. Meguid N, Anwar M, Zaki S, et al. Dietary patterns of children with autism spectrum disorder: a study based in Egypt. Open Access Maced J Med Sci. 2015;3(2):262-267. doi: doi: 10.3889/ oamjms.2015.051.

63. Ibrahim SH, Voigt RG, Katusic SK, et al. Incidence of gastrointestinal symptoms in children with autism: a populationbased study. Pediatrics. 2009;124(2):680-686. doi: 10.1542/ peds.2008-2933.

64. Konstantynowicz J, Porowski T, Zoch-Zwierz W, et al. A potential pathogenic role of oxalate in autism. Eur $J$ Paediatr Neurol. 2012;16(5):485-491.doi: 10.1016/j.ejpn.2011.08.004.

65. Halbrooks PJ, Mason AB, Adams TE, et al. The oxalate effect on release of iron from human transferring explained. $J \mathrm{Mol} \mathrm{Biol}$. 2004;339(1):217-226. doi: 10.1016/j.jmb.2004.03.049.

66. Luck AN, Bobst CE, Kaltashov IA, Mason AB. Human serum transferrin: Is there a link between autism, high oxalate and iron deficiency anemia? Biochemistry. 2013;52(46):8333-8341. doi: 10.1021/bi401190m.

67. Gebril $\mathrm{OH}$, Meguid NA. HFE gene polymorphisms and the risk for autism in Egyptian children and impact on the effect of oxidative stress. Dis Markers. 2011;31(5):289-294. doi: 10.3233/DMA2011-0830.

68. Han Y, Xi QQ, Dai W, et al. Abnormal transsulfuration metabolism and reduced antioxidant capacity in Chinese children with autism spectrum disorders. Int J Dev Neurosci. 2015;46:27-32. doi: 10.1016/j.ijdevneu.2015.06.006.

69. Bener A, Khattab A, Bhugra D, Hoffmann GF. Iron and vitamin D levels among autism spectrum disorders children. Ann Afr Med. 2017;16(4):186-191. doi: 10.4103/aam.aam_17_17.

70. Youssef J, Singh K, Huntington N, et al. Relationship of serum ferritin levels to sleep fragmentation and periodic limb movements of sleep on polysomnography in autism spectrum disorders. Pediatr Neurol. 2013;49(4):274-278. doi: 10.1016/ j.pediatrneurol.2013.06.012.

71. Lane R, Kessler R, Buckley AW, et al. Evaluation of periodic limb movements in sleep and iron status in children with autism. Pediatr Neurol. 2015;53(4):343-349. doi: 10.1016/ j.pediatrneurol.2015.06.014.

72. Al-Farsi YM, Waly MI, Al-Sharbati MM, et al. Levels of heavy metals and essential minerals in hair samples of children with autism in Oman: a case-control study. Biol Trace Elem Res. 2013;151(2):181-186. doi: 10.1007/s12011-012-9553-z.

73. Skalny AV, Simashkova NV, Skalnaya AA, et al. Assessment of gender and age effects on serum and hair trace element levels in children with autism spectrum disorder. Metab Brain Dis. 2017;32(5):1675-1684. doi: 10.1007/s11011-017-0056-7.

74. Скальная А.А., Бердалин А.Б., Кабки Б.Х., Жегалова И.В. Взаимосвязь между клиническими параметрами и элементным статусом детей до и после лечения // Микроэлементы в медицине - 2017. - T. 18. - № 4- C. 41-48. [Skalnaya AA, Berdalin AB, Kabki BH, Zhegalova IV. The relationship of clinical parameters and elemental status of children with autism before and after treatment. Mikroelementy $v$ meditsine. 2017;18(4): 41-48. (In Russ).]

75. Saghazadeh A, Ahangari N, Hendi K, et al. Status of essential elements in autism spectrum disorder: systematic review and meta-analysis. Rev Neurosci. 2017;28(7):783-809. doi: 10.1515/ revneuro-2017-0015.

76. Blaurock-Busch E, Amin OR, Dessoki HH, Rabah T. Toxic metals and essential elements in hair and severity of symptoms among children with autism. Maedica (Buchar). 2012;7(1):38-48. 